\title{
Extraction of Aspirated Headscarf Pins with Fiberoptic Bronchoscopy
}

\author{
Ahmed I. Al-Azzawi1,2 \\ ${ }^{1}$ Department of Thoracic and Cardiovascular Surgery, Sulaimaniyah Teaching Hospital, Sulaimaniyah, Iraq \\ ${ }^{2}$ Unit of Thoracic and Cardiovascular Surgery, School of Medicine, Faculty of Medical Sciences, University of Sulaimaniyah, \\ Sulaimaniyah, Iraq \\ Email: alazzawi_69@yahoo.com
}

How to cite this paper: Al-Azzawi, A.I (2017) Extraction of Aspirated Headscarf Pins with Fiberoptic Bronchoscopy. World Journal of Cardiovascular Surgery, 7, 143149.

https://doi.org/10.4236/wjcs.2017.712016

Received: November 2, 2017

Accepted: December 4, 2017

Published: December 7, 2017

Copyright (c) 2017 by author and Scientific Research Publishing Inc. This work is licensed under the Creative Commons Attribution International License (CC BY 4.0).

http://creativecommons.org/licenses/by/4.0/

\section{(c) (i) Open Access}

\begin{abstract}
Background: Foreign body aspiration is a common yet preventable health problem. Headscarf pin aspiration is a unique example of aspirated foreign bodies in young Muslim women usually removed using the rigid bronchoscope. However, the flexible bronchoscope is increasingly used for this purpose. This prospective study was conducted in Sulaimaniyah Teaching Hospital, Sulaimaniyah, Iraq and aimed to evaluate the usefulness of fiberoptic bronchoscope for removal of aspirated headscarf pins in view of the relevant literature. Methodology: Fifty female patients with headscarf pin aspiration were managed by fiberoptic bronchoscopy over an 8-year period (January 2008 to December 2015). The procedure was performed under local anesthesia and conscious sedation through the mouth. Results: The age ranged from 10 to 45 years with a mean of 27.5. All patients had cough, five had unilateral wheeze (10\%) while haemoptysis occurred twice (4\%). Fiberoptic bronchoscopy succeeded in 45 cases (90\%). Rigid bronchoscopy under general anesthesia was necessary in $(n=4,8 \%)$ while one patient $(2 \%)$ required thoracotomy. Conclusion: Fiberoptic bronchoscopy is safe and effective in removal of aspirated headscarf pins and should be tried first.
\end{abstract}

\section{Keywords}

Fiberoptic Bronchoscopy, Headscarf Pin Aspiration

\section{Introduction}

Foreign body aspiration (FBA) is frequently observed in children particularly before the age of 4 [1]. It can result in asphyxia and death and sometimes causes chronic pulmonary problems. The affected patients could be misdiagnosed as having pneumonia or bronchial asthma [2] [3] [4]. FBA is uncommon in adults 
[5], and only few large series have reported FBA in adults [6] [7] [8] [9]. The largest of these identified 62 adults over a period of 24 years [9]. Organic FBs are more common when compared to non-organic [10] [11].

A unique form of FBA is recently described among young Muslim girls who wear headscarves [12] [13] [14] [15] [16]. A sharp pin (headscarf or turban pin) is commonly used to hold the headscarf in place. The pin is about $4 \mathrm{~cm}$ in length with a smooth rounded pearl-like colored plastic head at one end (Figure 1). This beaded end is heavier than the rest of the pin and therefore the pin usually falls with the beaded end pointing downward. It is a common practice to hold the pin between the teeth or lips while both hands are used to adjust the head scarf. Aspiration usually happens during talking or laughing while the head is tilted backward.

The incidence of inhalation of this unique foreign body (FB) seems to be steadily increasing [17] [18]. The rigid bronchoscope (RB) is used to be the traditional method of removal [13] [14]. However, recently the fiberoptic bronchoscope (FOB) is increasingly reported to be used for this purpose [15] [16] [19] [20] [21]. The aim of this study is to explore the effectiveness and safety of FOB for extraction of aspirated headscarf pins.

\section{Patients and Methods}

This prospective study was performed at the Department of Thoracic and Cardiovascular surgery, Sulaimaniyah Teaching Hospital (STH), Sulaimaniyah, Iraq between January 2008 to December 2015. Informed written consent was taken from the 50 female patients who were enrolled in the study. The Ethical Committee of STH agreement to conduct the study has been obtained. Diagnosis of headscarf pin aspiration was established by typical history and plain chest radiography (Figure 2(A) and Figure 2(B)).

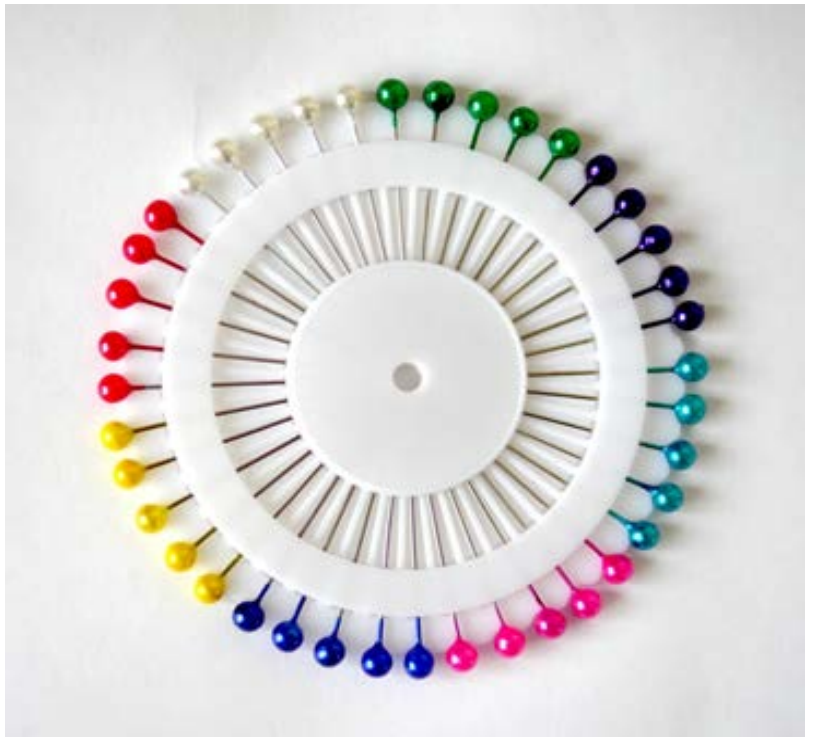

Figure 1. Headscarf pins with smooth rounded pearl-like heads. 

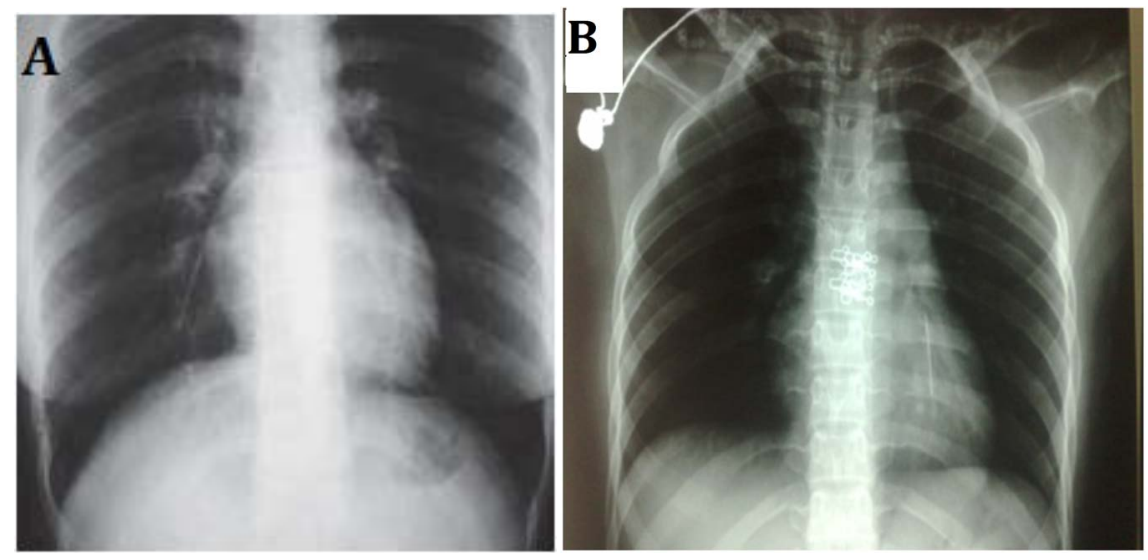

Figure 2. Chest radiographs showing headscarf pin in the right lower lobe (A) and in the left lower lobe (B).

Fiberoptic bronchoscopy was performed on day of admission. Olympus video-fiberoptic bronchoscope was used. Intravenous midazolam was used for sedation. Topical anesthesia was used with $5 \%$ lidocaine spray for the pharynx and $2 \%$ lidocaine for the larynx and the tracheobronchial tree. The bronchoscope was passed through the mouth. Pins were removed using a biopsy forceps (Figure 3) due to non-availability of foreign body forceps. Once a firm hold of the pin was secured, the grasping instrument was withdrawn to the tip of the bronchoscope, and then, the bronchoscope and the grasping instrument were both slowly withdrawn under direct vision. After removal of the pin, the bronchoscope was passed again to inspect any possible post extraction damage to the larynx, vocal cords or the tracheobronchial tree.

\section{Results}

All patients were previously healthy. Aspiration of headscarf pins has occurred as a result of sudden speech, coughing or laughing while the pin was between the lips or teeth. The mean age was 27.5 years (range 10 - 45 years). The time interval between aspiration and admission to our unit was less than 24 hours in 45 patients (90\%). The pin was found in the right side in 25 cases (50\%), in the left side in 22 cases (44\%), and in the trachea in 3 cases (6\%). All aspirated pins were found with the pearl head down and the sharp end embedded in the mucosa. The pin was successfully removed using FOB in 45 cases (90\%). Rigid bronchoscopy was needed in 4 cases (8\%). Thoracotomy was done in 1 case (2\%) after failure of FOB and RB. All patients were discharged home a few hours after completion of the procedure.

\section{Discussion}

Fiberoptic bronchoscopy has been used increasingly in the diagnosis and treatment of tracheobronchial diseases in recent years. Traditionally, RB has been the procedure of choice for removal of foreign bodies in children [20]. Nevertheless; 


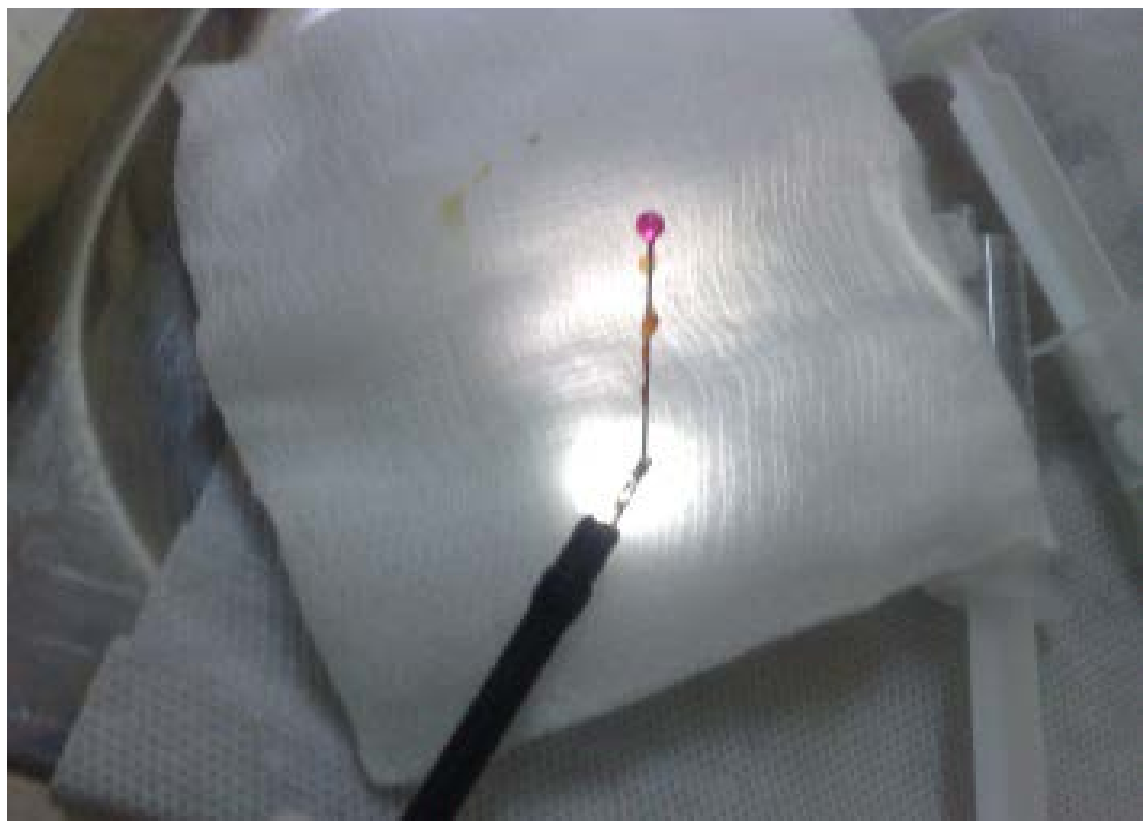

Figure 3. Removal of the pin by grasping its proximal end using the forceps. The removed headscarf pin is shown.

FOB is the gold standard for the diagnosis of airway foreign bodies and the preferred instrument for their removal in adults. Moreover, FOB is used increasingly in the treatment of the FBA in adults and children [22] [23]. The success rate of FOB removal varies between $86 \%$ and $100 \%$ [24] [25]. In most reported studies, sharp foreign bodies such as pins were removed using the RB [14], FOB [9] or both instruments [26].

In Iraq, the standard method for removal of bronchial foreign bodies remains rigid bronchoscopy [2]. It is of interest to note that the first Iraqi patient examined by FOB in 1976 by Dr. Azhar K Kassab (FRCS) was a man with chronic cough following inhalation of a small metallic coin 4 years earlier. FOB revealed a partial obstruction of the right bronchial tree by a dark-colored 25-fils coin which was successfully removed by the FOB without needing the rigid bronchoscope [27]. Recently, Taha AY [2] and Baram et al. [17] from Sulaimaniyah, Iraq reported their experience in using FOB to remove bronchial foreign bodies.

In the study carried out by Lan et al., FBs were successfully removed with FOB in all 33 adults except one [19]. The success rates of FOB have been reported as $56 \%, 62.5 \%$ and $80.6 \%$ in three studies [26] [28] [29] [30]. Fenane et al. reported that the average number of attempts of FOB removal was 2.5 times per patient [31]. Kaptanoglu et al. reported that they could extract all but six of a total of 63 patients in the first attempt [13].

In the study of Chen et al., the aspired material could be removed by one or more attempts of FOB in 34/43 patients (74\%) [8]. The reasons for unsuccessful endoscopy were reported as distal localization and pins embedded in bronchus wall with inflammatory reaction [31].

Limper et al. reported on 60 patients with FBA. RB was successful in $98 \%$ of 
cases while FOB achieved a $60 \%$ success rate only. Hence, they do not agree with the opinions arguing that the FOB should prevail compared to RB. However, they believe that FOB would be advantageous in certain situations such as foreign bodies beyond the reach of RB, FBA in ventilated patients and when the use of a $\mathrm{RB}$ is not possible due to the lack of cervical stabilization [6].

Due to the fact that the pin can travel down to the segmental bronchi, the FOB may be more successful in pin removal. The aspirated pins usually do not pose a risk of obstruction due to their small size. Traditionally, Muslim women start to wear a scarf at the onset of puberty; therefore, all patients in this study were either older children or young adults. The patients were co-operative enough to tolerate FOB under local anesthesia. Four patients required RB after failure of FOB. This could be due to implantation of the pins in bronchial mucosa and non-availability of a proper grasping FB forceps.

In previously reported series of headscarf (turban) pin aspiration, $\mathrm{RB}$ was the main procedure for pin removal [12] [13] [14]. FOB was used in 5/47 cases (11\%) by Ucan et al. [12] and in 2/63 cases (3\%) by Kaptanoglu et al. [13] but never (0/6) by Murthy et al. [20]. In contrast, other authors preferred FOB. In a series of 5 cases described by Shabb et al. [15], FOB under general anesthesia was used in all cases. Recently, Gokirmak et al. [16] retrospectively reported the usefulness of FOB under local anesthesia in the retrieval of $8 / 11$ aspirated turban pins (73\%).

A potential complication of the approach with FOB under conscious sedation and local anesthesia is the risk of injury to the larynx or tracheobronchial tree during extraction of aspirated pins. In this study, we did not encounter such complications. Another potential complication is the risk of losing the pin in the throat. The pin is then quickly swallowed and settles in the stomach. We did not encounter such a complication. FBA is a frightening event. Most of our patients experienced extreme stress and panic. Therefore, sedation was necessary and proved to be helpful.

In this study, the distribution of aspirated pins in the tracheobronchial tree was similar to previous reports [12] [13]. Fifty \% of the pins were found in the right bronchial system (due to wider caliber of right main bronchus and being more in line with the trachea than the left bronchus). The lower lobe bronchus predominated as site of pin settlement as the aspiration occurred while the patients were standing up.

The number of patients involved in the present study was relatively good. However, a major limitation to the study was the unavailability of a proper grasping foreign body forceps.

\section{Conclusion}

In summary, aspiration of headscarf pin is a serious event in Muslim culture. Prevention can be achieved by improving public awareness and wearing a type of headscarf that does not need a pin for fixation. Once it occurs, immediate 
medical consultation is mandatory. Fiberoptic bronchoscopy is safe and effective for removal of these pins and should always be tried first.

\section{References}

[1] Black, R.E., Choi, K.J., Syme, W.C., Johnson, D.G. and Matlak, M.E. (1984) Bronchoscopic Removal of Aspirated Foreign Bodies in Children. The American Journal of Surgery, 148, 778-781. https://doi.org/10.1016/0002-9610(84)90436-7

[2] Taha, A.Y. (2013) The Use of Fiberoptic Bronchoscope to Remove Aspirated Tracheobronchial Foreign Bodies: Our Experience. Case Reports in Clinical Medicine, 2, 285-290. https://doi.org/10.4236/crcm.2013.25077

[3] Elhassani, N.B. (1988) Tracheobronchial Foreign Bodies in the Middle East. Baghdad Study. The Journal of Thoracic and Cardiovascular Surgery, 96, 621-625.

[4] Kula, O., Gurkan, S., Latinos, H., et al. (2003) Foreign Body Aspiration in Infants and Children. Turkish Respiratory Journal, 4, 76-78.

[5] Rizk, N., Gwely, N., Biron, V., et al. (2010) Metallic Hair Pin Inhalation: A Health Care Problem Facing Young Muslim Females. Journal of Otolaryngology-Head \& Neck Surgery, 267, 1957-1962.

[6] Limper, A.H. and Prakash, U.B. (1990) Tracheobronchial Foreign Bodies in Adults. Annals of Internal Medicine, 112, 604-609.

https://doi.org/10.7326/0003-4819-112-8-604

[7] Lan, R.S. (1994) Non-Asphyxiating Tracheobronchial Foreign Bodies in Adults. The European Respiratory Journal, 7, 510-514.

https://doi.org/10.1183/09031936.94.07030510

[8] Chen, C.H., Lai, C.L., Tsai, T.T., et al. (1997) Foreign Body Aspiration into the Lower Airway in Chinese Adults. Chest, 112, 129-133. https://doi.org/10.1378/chest.112.1.129

[9] Debeljak, A., Sorli, J., Music, E. and Kecelj, P. (1999) Bronchoscopic Removal of Foreign Bodies in Adults: Experience with 62 Patients from 1974-1998. The European Respiratory Journal, 14, 792-795. https://doi.org/10.1034/j.1399-3003.1999.14d11.x

[10] Weissberg, D. (1992) Foreign Bodies in the Tracheobronchial Tree. Chest, 2, 656. https://doi.org/10.1378/chest.102.2.656b

[11] Ciftci, A.O., Bingol-Kologlu, M., Senocak, M.E., Tanyel, F.C. and Buyukpamukcu, N. (2003) Bronchoscopy for Evaluation of Foreign Body Aspiration in Children. Journal of Pediatric Surgery, 38, 1170-1176. https://doi.org/10.1016/S0022-3468(03)00263-X

[12] Ucan, E.S., Tahaoglu, K., Mogolkoc, N., Dereli, S., Basozdemir, N., Basok, O., et al. (1996) Turban Pin Aspiration Syndrome: A New Form of Foreign Body Aspiration. Respiratory Medicine, 90, 427-428. https://doi.org/10.1016/S0954-6111(96)90117-1

[13] Kaptanoglu, M., Dogan, K., Onen, A. and Kunt, N. (1999) Turban Pin Aspiration; a Potential Risk for Young Islamic Girls. International Journal of Pediatric Otorhinolaryngology, 48, 131-135. https://doi.org/10.1016/S0165-5876(99)00020-8

[14] Murthy, P.S.N., Ingle, V.S., George, E., Ramakrishna, S. and Shah, F.A. (2001) Sharp Foreign Bodies in the Tracheobronchial Tree. American Journal of Otolaryngology, 22, 154-156. https://doi.org/10.1053/ajot.2001.22585

[15] Shabb, B., Taha, A.M., Hamada, F. and Kanj, N. (1996) Straight Pin Aspiration in Young Women. Journal of Trauma, 40, 827-828.

https://doi.org/10.1097/00005373-199605000-00026 
[16] Gokirmak, M., Hasanoglu, H.C., Koksal, N., Yildirim, Z., Hacievliyagil, S.S. and Soysal, O. (2002) Retrieving Aspirated Pins by Flexible Bronchoscopy. Journal of Bronchology, 9, 10-14. https://doi.org/10.1097/00128594-200201000-00004

[17] Baram, A., Kakamad, F.H. and Bakir, D.A. (2015) Scarf Pin Related Hijab Syndrome: A New Name of an Unusual Type of Foreign Body Aspiration. Journal of International Medical Research, 1-7.

[18] Salih, A.K. (2015) Use of FOB for Removal of Inhaled Endobronchial Headscarf Pin in Adults. TQMJ, 10, 175-184.

[19] Lan, R.S., Lee, C.H., Chiang, Y.C. and Wang, W.J. (1989) Use of Fiberoptic Bronchoscopy to Retrieve Bronchial Foreign Bodies in Adults. The American Review of Respiratory Disease, 140, 1734-1737. https://doi.org/10.1164/ajrccm/140.6.1734

[20] Martinot, A., Closset, M., Marquette, C.H., Hue, V., Deschildre, A., Ramon, P., et al. (1997) Indications for Flexible versus Rigid Bronchoscopy in Children with Suspected Foreign Body Aspiration. American Journal of Respiratory and Critical Care Medicine, 155, 1676-1679. https://doi.org/10.1164/ajrccm.155.5.9154875

[21] Swanson, K.L., Prakash, U.B., Midthun, D.E., Edell, E.S., Utz, J.P., McDougall, J.C., et al. (2002) Flexible Bronchoscopic Management of Airway Foreign Bodies in Children. Chest, 121, 1695-1700. https://doi.org/10.1378/chest.121.5.1695

[22] Chen, W., Cheng, D. and Ji, C. (1999) The Diagnostic and Therapeutic Value of Flexible Bronchoscopy in Foreign Body Aspiration Misdiagnosed as Other Respiratory Diseases. Journal of Huaxi Medical University, 30, 327-328.

[23] Gerritsen, J. (2003) Flexible Bronchoscopy in Children: An Open Airway. The European Respiratory Journal, 22, 576-577. https://doi.org/10.1183/09031936.03.00084102

[24] Rafanan, A.L. and Mehta, A.C. (2004) Bronchoscopy in Foreign Body Removal. In: Wang, K.P., Mehta, A.C. and Turner, J.F., Eds., Flexible Bronchoscopy, 2nd Edition, Blackwell, Malden, 197-209.

[25] Rafanan, A.L. and Mehta, A.C. (2001) Adult Airway Foreign Body Removal: What's New? Clinics in Chest Medicine, 22, 319-330. https://doi.org/10.1016/S0272-5231(05)70046-0

[26] Ruegemer, J.L. and Perkins, J.A. (1999) Combined Rigid and Flexible Endoscopic Removal of a BB Foreign Body from a Peripheral Bronchus. International Journal of Pediatric Otorhinolaryngology, 47, 77-80. https://doi.org/10.1016/S0165-5876(98)00164-5

[27] Taha, A.Y. (2017) The History of Introducing the Fiberoptic Bronchoscopy in Iraq. Journal of the Egyptian Society of Cardiothoracic Surgery. https://doi.org/10.1016/j.jescts.2017.11.003

[28] Hebbazi, A., Afif, H., El Khattabi, W., Aichane, A. and Bouayad, Z. (2010) Scarf Pin: A New Intra-Bronchial Foreign Body. Revue des Maladies Respiratoires, 27, 724-728. https://doi.org/10.1016/j.rmr.2010.06.021

[29] Zaghba, N., Benjelloun, H., Bakhatar, A., Yassine, N. and Bahlaoui, A. (2013) Scarf Pin: An Intra-Bronchial Foreign Body Who Is Not Unusual. Revue De Pneumologie Clinique, 69, 65-69. https://doi.org/10.1016/j.pneumo.2012.09.003

[30] Al-Ali, M.A., Khassawneh, B. and Alzoubi, F. (2007) Utility of Fiberoptic Bronchoscopy for Retrieval of Aspirated Headscarf Pins. Respiration; International Review of Thoracic Diseases, 74.

[31] Fenane, H., Bouchikh, M., Bouti, K., EL Maidi, M., Ouchen, F., Mbola, T.O., et al. (2015) Scarf Pin Inhalation: Clinical Characteristics and Surgical Treatment. Journal of Cardiothoracic Surgery, 10, 61. https://doi.org/10.1186/s13019-015-0268-Z 